\title{
Effect of Crack Repair by Bio-Based Materials Using Alginate and Bacillus Subtilis under Wet and Dry Environment Part-II
}

\author{
Takahiro Nishida ${ }^{1}$, Keiyu Kawaai ${ }^{2}$ and Atsushi Saito ${ }^{3}$ \\ ${ }^{1}$ National Research and Development Agency, National Institute of Maritime, Port and \\ Aviation Technology, Port and Airport Research Institute, Japan, nishida-ta@p.mpat.go.jp \\ ${ }^{2}$ Civil and Environmental Engineering, Ehime University, 3, Bunkyocho, Matsuyama, Ehime, \\ Japankkawaai@cee.ehime-u.ac.jp \\ ${ }^{3}$ Reseach Center, Hazama Ando Corporation, Japan, atsushi.saito@ad-hzm.co.jp

\begin{abstract}
This study examined durability of mortar after repairing crack using alginate gel films (1.5 wt.\%) mixed with healing agents under seawater splayed condition. The healing agents consist of Bacillus subtilis (natto) as an aerobic microorganism and glucose as an organic carbon source, thereby producing insoluble calcium carbonate in the gel films in the presence of calcium ions. In this study, repaired mortar was dried under room condition for half year and exposed at seawater splayed condition for another half year. After that, surface condition, elastic wave velocity was measured. In addition, the inside situation in the crack was observed by X ray computed tomography. Based on the results of elastic wave velocity, the property of repair material in mortar was improved under the seawater splayed condition. Additionally the substance in crack derived from healing agents was remained even after seawater splayed exposure.
\end{abstract}

Keywords: Self-Healing, Aerobic Microorganisms, Bio-Composite, Seawater Splayed Exposure.

\section{Introduction}

Recently, repair materials associated with microbial induced calcium carbonate precipitation (MICCP) have been intensively studied in the field of self-healing concrete e.g. (Jonkers et al., 2010). We proposed a liquid based repair system comprising dry yeast, organic carbon sources, calcium sources mixed with Tris alkali buffering solution (Kawaai et al., 2016; Putri at el., 2016). The grout used for repairing cracks in concrete is supposed to seep into deeper zones in cracks, joints and gaps spatially distributed in larger areas. Then, calcium carbonate precipitation mainly contributing to the sealing effect can be formed in the cracks well before 24 hours (Kawaai et al., 2016). It has been reported that the precipitation rate was largely dependent on the concentration of constituents, $\mathrm{pH}$ levels, and ambient environment such as temperature. The effect of temperature is significant in facilitating the precipitation process (Putri et al., 2016), thus leading to a larger amount of precipitates formed compared to those tested in normal room conditions.

Apart from the grout system, the activity of Bacteria added to mixing water was observed to be limited owing to the pore solution with highly alkaline environment (Jonkers, 2011). In order to protect them from corrosive agents and the severe environment, much research has been carried out in the development of encapsulation techniques including expanded clay particles, glass tubes, superabsorbent polymer, more recently alginate-based systems (Jonkers, 2011; Tittleboom et al., 2011; Wang et al., 2014; Palin et al., 2016). 
According to past research reported by Kawaai et al., (2017), precipitation of calcium carbonate in alkaline environment has been confirmed by precipitation tests using aerobic Bacillus subtilis (natto) encapsulated in calcium alginate capsules. Sodium alginate extracted from brown seaweed could provide viscosity in aqueous solution, which varies depending on the concentrations. When sodium alginate dissolved in a liquid is used for repairing cracks in concrete, there is a strong possibility that the alginate reacts with calcium ions available on the cracked surface, thus forming a polymer comprising calcium alginate via ion-link on the cracked surface. This could result in in-situ encapsulation for the microorganism and nutrients in the cracks. Generally, there are two types of microorganisms, anaerobic and aerobic microorganisms. The former can metabolize an organic carbon sources in an oxygen-free environment. On the other hand, the latter requires oxygen for the metabolic activity. In this study, we selected Bacillus subtilis (natto) as an aerobic microorganism. The liquid-based mixture is supposed to be applied to concrete structures in tidal zones under marine environment. Dissolved oxygen is expected to be available during the wet and dry cycles. Based on the above background, this study examines the durability of repaired mortar under seawater splayed environment.

\section{Experimental Programs}

\subsection{Materials}

\section{First, culture solution stirrer for 30 minutes or glucose is added. Table 1. The experinne mixture) of Bacillus surt wt. $\%$ for all the mixtures tested. The use of
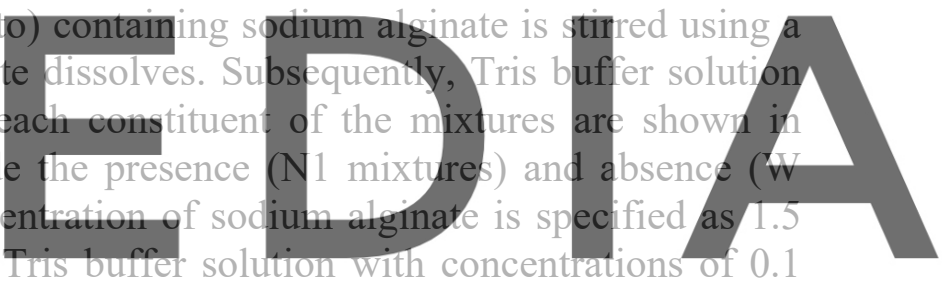 $\mathrm{mol} / \mathrm{L}$ is also considered as a testing parameter. In this study, three mixtures were totally \\ Register foreffeet.at https//www.scipedia.com to download the version without the watermark}

Table 1. Concentrations of each constituent of mixtures.

\begin{tabular}{ccccc}
\hline & Mixtures & $\begin{array}{c}\text { Sodium Alginate } \\
(\%)\end{array}$ & $\begin{array}{c}\text { Glucose } \\
(\mathrm{mol} / \mathrm{L})\end{array}$ & $\begin{array}{c}\text { Tris buffering solution } \\
(\mathrm{mol} / \mathrm{L})\end{array}$ \\
\hline \multirow{2}{*}{ N1 } & N1-G1-T0 & 1.5 & 0.4 & - \\
& N1-G1-T1 & 1.5 & 0.4 & 0.10 \\
\hline W & W -G0-T0 & 1.5 & - & - \\
\hline
\end{tabular}

\subsection{Cultivation of Bacillus Subtilis (Natto)}

In this study, Bacillus subtilis (natto) was cultivated using culture media mainly comprising $\mathrm{NH}_{4} \mathrm{Cl}, \mathrm{NH}_{4} \mathrm{NO}_{3}, \mathrm{Na}_{2} \mathrm{SO}_{4}, \mathrm{MgSO}_{4}, \mathrm{CaCl}_{2}, \mathrm{~K}_{2} \mathrm{HPO}_{4}, \mathrm{KH}_{2} \mathrm{PO}_{4}$ in this study. The round rod shape of Bacillus subtilis (natto) forms a spore per a bacterial cell in the bacterial body. 
Spores are formed when it becomes an environment not suitable for growth such as oxygen, water and nutrient sources. And then, they become dormant and inactive. However, if the environment is set, the spore dormancy state ends, and germination begins. And then it becomes vegetative cell and the activity starts. Therefore, the Bacillus subtilis (natto) has higher resistance to environmental fluctuation compared to other microorganisms. In this study, the culture solution of the Bacillus subtilis (natto) after 24 hours was used as repair mixtures. Before preparing the mixtures, the dissolved oxygen concentration in the culture solution was measured to confirm the metabolic activity of Bacillus subtilis (natto) without an aeration apparatus.

\subsection{Specimen Preparation and Exposure Tests}

In this study, a mortar specimen with a water cement ratio of 0.5 and unit water content of $316 \mathrm{~kg} / \mathrm{m}^{3}$ and unit weight of crushed sand $1264 \mathrm{~kg} / \mathrm{m}^{3}$ was prepared using a cylindrical mold of $\phi 50 \times 100 \mathrm{~mm}$. Specimens were demolded after 24 hours and sealed curing was carried out until the age of 28 days. In order to simulate the cracks generated in the concrete member, split cracks were induced using a loading machine. The experimental set-up is similar to tensile strength test. The crack width was targeted around $0.5 \mathrm{~mm}$. And then, the repair mixtures were poured into the cracks. After 1 week, exposure tests were carried out either through wet conditions (12 hours) and dry conditions (12 hours) or only wet conditions (24 hours). Wet cycles were executed using distilled water containing $\mathrm{NaCl}(3 \%)$ for both cases.
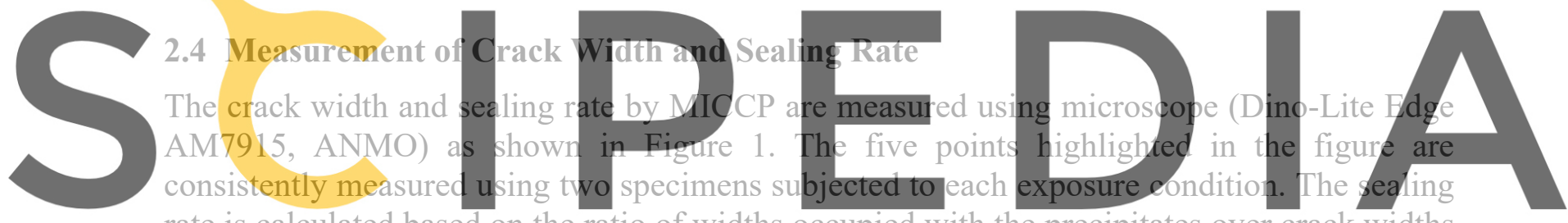
rate is calculated based on the ratio of widths occupied with the precipitates over crack widths

Register for free at https//wWW.scipedia.com to download the version without the watermark

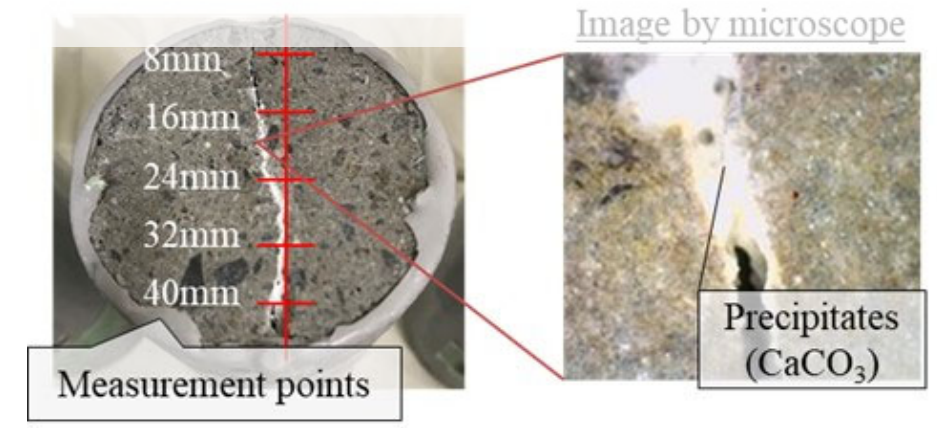

Figure 1. Measurement of crack width and sealing rate by microscope.

\subsection{Exposure Condition after Repairing}

The specimen after repairing was exposed to seawater splayed condition. The seawater was pumped up from Kurihama bay and splayed to specimens as shown in Figure 2. Seawater was splayed twice in a day and specimen was exposed for 6 months. 


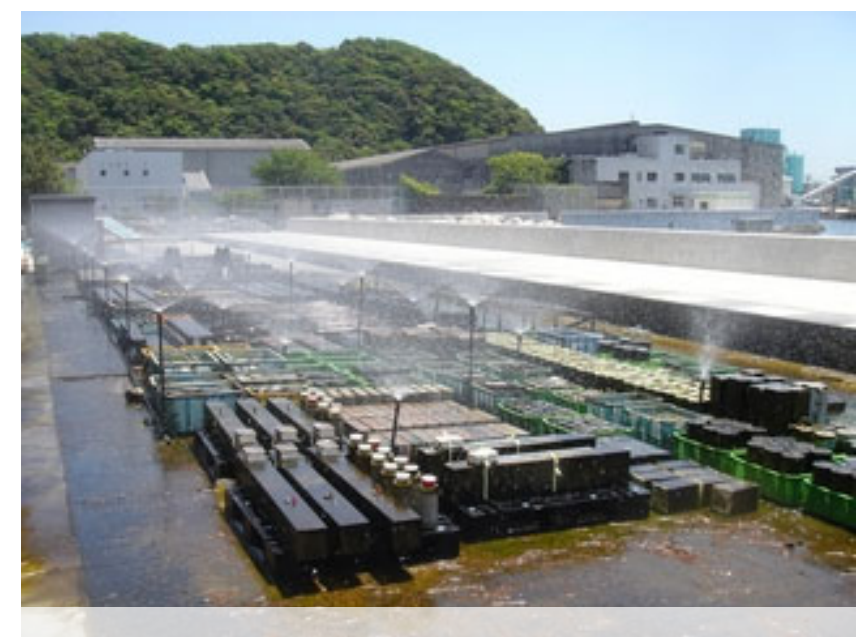

Figure 2. Seawater splayed environment.

\subsection{Measurement of Elastic Wave Velocity}

In order to evaluate the crack filling effect of self-healing material, the elastic wave velocity was measured every 1 month after exposure test. Elastic wave velocity can evaluate the connectivity of materials at crack part and the value increase with the crack filling due to deposition of healing schematic figure of mea surface of specimen ans were evaluated.
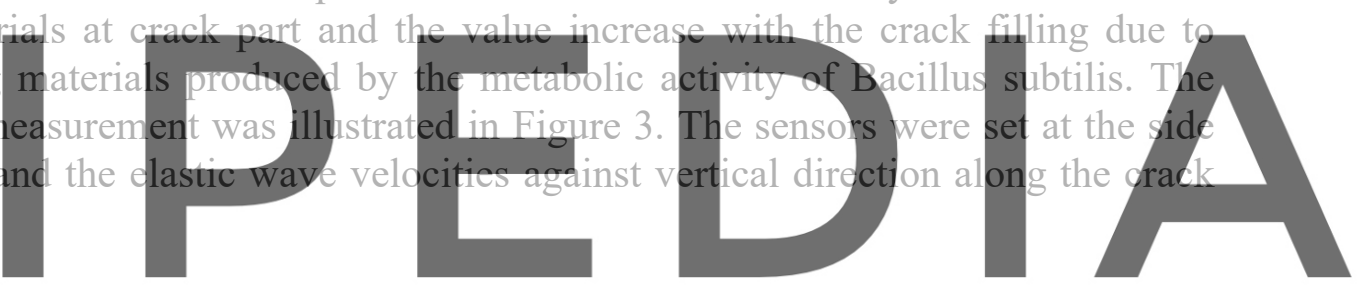

Repaired crack

Register for free at https//www.scipedia.com to download the version without the watermark

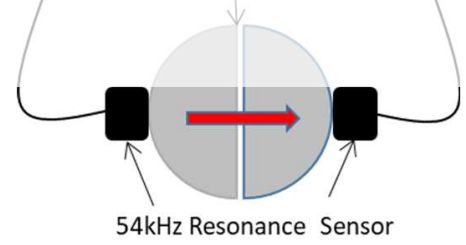

Figure 3. Measurement outline of elastic wave velocity.

\section{Experimental Results and Discussion}

\subsection{Results of Elastic Wave Velocity}

The elastic wave velocity of each specimen exposure to seawater splayed condition after 0 , 30, 90, 180 days is shown in Figure 4. Before exposure to seawater splayed condition, the specimens were exposed to experimental room (20 degree centigrade and $60 \%$ R.H.) and specimens were dried. Therefore the results of all of elastic wave velocity of specimens before exposure were equivalent to cracked mortar. After exposed to seawater splayed environment, 
the elastic wave velocities of mortar with crack were increased. Especially in the cases of specimen with Bacillus subtilis, the elastic wave velocities of specimen were clearly increased.

It was assumed that the repair substance inside of crack remained and the elastic wave penetrate that part. Figure 5 show the result of X ray CT in crack after 180 days exposure. From this figure, it can be said that the substance produced by Bacillus subtilis were remained inside of crack even after exposed to seawater splayed condtion.

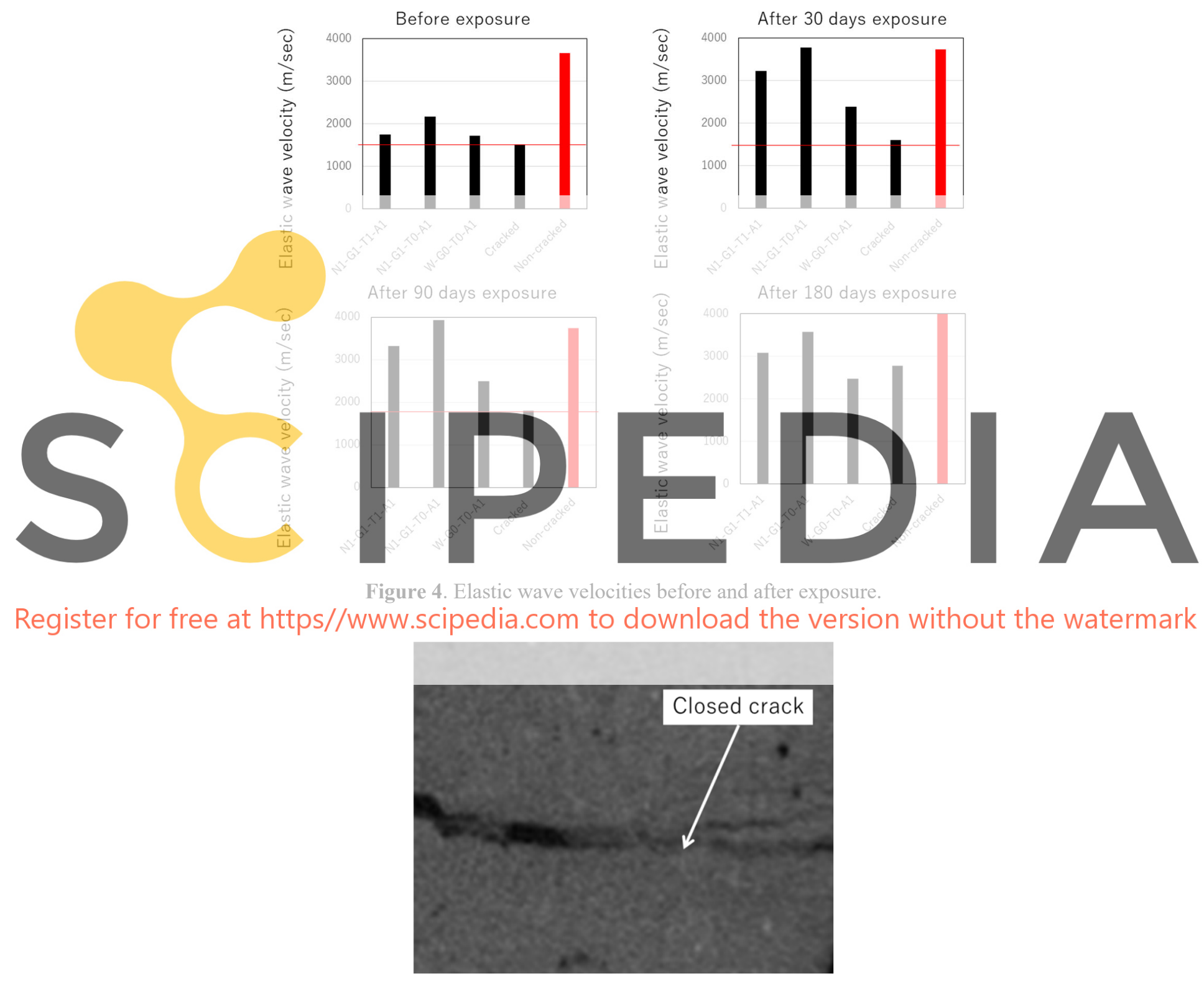

Figure 5. Crack closure situation after exposure for 6 months under seawater splayed condition. 


\section{Conclusions}

- Based on the observations made on the sealing rate of crack repair, the presence of gel films remained intact on the cracked surface under exposure conditions could contribute to higher sealing effect in the cases of the N1 mixtures.

- The results suggest that the repair effect of crack produced by Bacillus subtilis would be kept even after exposed to seawater splayed condition.

\section{Acknowledgements}

This study is financially supported by JSPS KAKENHI Grant-in-Aid for Scientific Research (B), Grant numbers $19 \mathrm{H} 02216$.

\section{ORCID}

Takahiro Nishida: https://orcid.org/0000-0002-2018-6928

Keiyu Kawaai: https://orcid.org/0000-0003-4767-4355

Atsushi Saito: https://orcid.org/0000-0001-6866-1882

\section{References}

Jonkers, H.M., Thijssen, A., Muyzer, G., Copuroglu, O. and Schlangen, E. (2010). Application of bacteria as self-healing agent for the development of sustainable concrete, Ecological Engineering, 36, 230-235.

Kawaai, K., Ujike, I., Yamamoto, S. and Putri, P.Y. (2016). Some considerations on precipitation rate of calcium carbonate in bio-based materials uned for concrete repair, Concrete Solutions 2016, 6th International Conference on Concrete Repair,

Putri, P.Y., Kawaai, K., Ujo Calcium Carbonate Produced t Dimension, 18(2), 103-108.

Jonkers, H.M. (2011). Batteria-based self-healing concr te, Tittelboom, K.V., Belie, ND., Loo, D.V. and Jacobs, P.

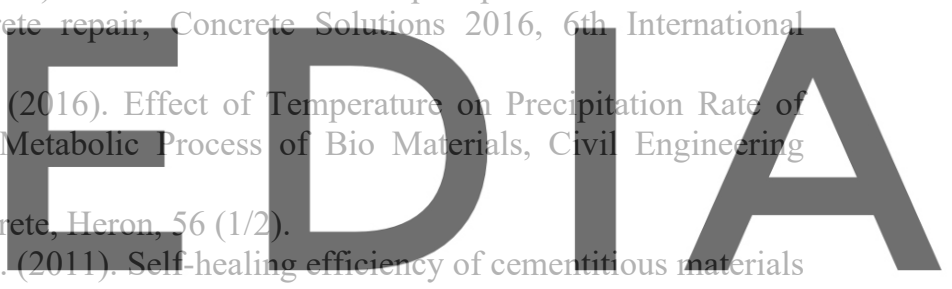
containing tubular capsules filled with healing agent, Cement and concrete Composites, 33, 497-505, 2011.

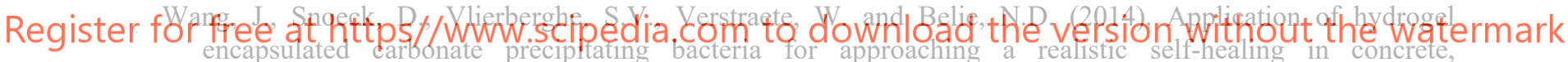
Construction and Building Materials, 68, 110-119.

Palin, D., Wiktor, V. and Jonkers, H.M. (2016). A bacteria-based bead for possible self-healing marine concrete applications, Smart Materials and Structures, 25(8).

Kawaai, K., Nishida, T. and Saito, A. (2017). Calcite-alginate bio-composite formation in alginate gel films for self-healing concrete application, Proceedings of the 5th Seminar Workshop on the Utilization of Waste Materials in conjunction with the 2nd International Symposium on Concrete and Structure for the Next Generation, Manila Philippines, 5. 